\title{
Journey of Surgical Mask : from Bra to N 95 in COVID -19
}

\author{
Kaushik Bhattacharya ${ }^{1}$, Neela Bhattacharya ${ }^{2}$ \\ 'CAPFs Composite Hospital BSF Kadamtala, Siliguri, West Bengal, India \\ ${ }^{2}$ Anandaloke Multispeciality Hospital, Siliguri, West Bengal, India
}

Keywords: Face mask; respirator; aerosol; pandemic; lockdown

\begin{abstract}
The role of the surgical mask during COVID-19 pandemic is undoubtedly very vital in preventing infections. A review of the evolution of the face mask from the animal bladder of the past to the present $\mathrm{N} 95$ is being done with an emphasis on the importance and problems currently faced by the surgical community due to constant wearing of $\mathrm{N} 95$ mask in the hospital. Though N 95 mask is the ideal mask during Coronavirus pandemic, there are a few issues like carbon dioxide retention and headache which is hampering its prolonged use.
\end{abstract}

\section{Introduction}

"If I could choose, I would rather save 100 million lives than 100 million dollars " - Peter Tsai ( Brain behind N 95 surgical mask )

In the ongoing COVID-19 pandemic, Facemask is one of the most important parts of Personal Protection Equipment (PPE) for health care professionals in the hospitals and civilians conferring essential services during the ongoing Coronavirus pandemic. Gaius Plinius Secundus of Rome, 2000 years ago, conceptualized the first design of respirator to protect the Roman miners from the toxic dust of red lead oxide and involved using an animal bladder. It is also reported that Leonardo Da Vinci had suggested a respirator made of wet woven cloth to filter out a poison gas weapon he had invented. Thereafter a brief lull, it was in the year 1340 when 'Beak Mask' was used to keep away the stench during the time of Plague. Even today the iconic symbol of Black Death is the Beak Mask. According to the history of Medicine, the invention of the 'Beak doctor' costume is attributed to a French doctor Charles De Lorme, who served as chief physician of three French kings- Henri IV, Louis XIII and Louis XIV. He is credited with the design of the bird mask

Correspondence: Kaushik Bhattacharya

E-mail: kbhattacharya10@yahoo.com

(iD) https://orcid.org/0000-0002-4825-9148

Received: 11-05-2020 Accepted: 18-08-2020

DOI: http://doi.org/10.4038/sljs.v38i2.8696 which was to be worn with a large waxen coat as a form of head to toe protection in the year 1619 ('medico della peste costume'). During the bubonic plague when visiting sick patients in quarantine, the special costume was designed for the doctors which included a beak filled with perfumes along with either sweet or strong smelling substances like lavender, along with gloves, boots, hat and official robe made of a particular type of leather made from the skins of goats, sheep, or seals, having irregular creases. (Levantine leather) [1]. It was probably the first step toward the modern-day PPE. Alexander Von Homboldt developed a mask with rubber in 1799 and John Stenhouse discovered that various form of Charcoal could capture and hold gas, thus pioneering activated charcoal filter. John Scott Haldane developed the first gas mask, that could protect against Chlorine gas attack during the war. In 1897, doctors started wearing the first surgical masks, a glorified version of handkerchiefs.

\section{The arrival of the modern mask}

The cloth face mask was designed by Wu Lien-teh in 1910 when a contagious pneumonic plague was ravaging northeastern China. Wu Lien-the, a Cambridge scholar concluded that the disease is airborne and so he adopted the technique to wear mask using layers of cotton and gauze, a procedure he had seen in England. During Manchurian plague outbreak, Wu was able to conduct the epidemic's first postmortem ( usually banned in China at that time ) on a Japanese woman who had died of Plague and was able to identify the organism responsible, Yersinia pestis. $\mathrm{Wu}$ was able to convince the Russian as well as the Japanese authorities to strictly cremate the dead and also recommended cancelling trains, thereby isolating Manchuria and thereby preventing the spread of the disease.

He was able to initiate the concept of first-ever modern-day 'lockdown'. Having concluded with the autopsy that the Plague was spreading by air, $\mathrm{Wu}$ advocated the use of a surgical mask. One French doctor Dr Gerald Mesny dismissed his mask with this racist comment, "What can we expect from a China man ?"Mesny went on to work without a mask, caught the plague and succumbed to the disease shortly after [2]. It is believed that the present N95 mask is a descendent of Wu's design. 


\section{The arrival of $\mathrm{N} 95$ mask}

In 1961, 3M released bubble surgical mask, the design took inspiration from the moulded cup of a bra.

In 1992 Peter Tsai from Taiwan lead a team at the University of Tennessee and attempted to develop the electrostatic filtration technology. It was a successful research and led to the creation of $\mathrm{N} 95$ face mask. Tsai used a method called corona electrostatic charging in producing the N 95 masks, whose filters help block and contain a minimum of $95 \%$ of all particles. Tsai retired from the University of Tennessee in 2019. However, with the single-use N95 masks in short supply due to the COVID-19 coronavirus pandemic, he came out of retirement to study ways in which to disinfect the masks so that they could be safely reused. Maha Krishnamurty, Vice President of the University of Tennessee Research Foundation told Tsai once "You seem to be the man of the hour" and Tsai replied, "No, I am the man of the minute!"

While Tsai's friends have joked that he could be making a fortune, now that his expertise is in such high demand, he said that money has never been his primary motivation. He said “ The front line hospital workers - they are heroes. I am just trying to help them wear the mask".

\section{The saga of $\mathrm{N} 95$ mask}

In 1972, the first single-use N 95 "dust" respirator was developed by $3 \mathrm{M}$.

The ' $\mathrm{N}$ ' in the respirator name denotes 'not resistant to oil' and ' 95 ' means the ability to remove $95 \%$ of submicron ( 0.3 microns) particle-like influenza virus, dust, pollen, haze and smoke. Initially, N 95 mask was used in the industrial sector in the 1950 s to prevent getting black lung disease during coal mining. Its use as a mask in medicine was established during the 2009 H1N1 pandemic. Currently, N 95 mask is one of the main armamentariums of PPE for the health care workers working in this pandemic. It has been documented that the nanoparticles which mainly travel by Brownian motion, are effectively captured within the N95 filter via mechanical and electrostatic forces, even though viral particles are sometimes smaller than this. The outer side of the mask material is typically hydrophobic polypropylene.

The most useful aspect of the N95 mask is its. extended use. It can also be reused but re-processing of masks all invariably does affect the filtration capacity of the mask. N95 respirators can be decontaminated and re-used in times of shortage for up to three times by using Ultraviolet radiation $(260-285 \mathrm{~nm})$ and vaporized hydrogen peroxide, and up to two times by dry heat [3].

\section{Problems with N95 mask}

\section{"N 95 masks are a pain to wear" - Elon Musk (Tesla and Space X CEO)}

In a controlled clinical study, it was seen that those who were wearing N 95 mask, their effect on pregnant healthcare workers lead to the impediment of the gaseous exchange and it led to an additional workload on the metabolic system [4]. Wearing N 95 mask for a long duration may induce physiological stress which can make regular tasks difficult and may cause a headache amongst health care providers, due to the respiratory microclimate change surrounding the mask [5]. It was seen that the nasal resistance was not recovered even after 1.5 hours removal of the facemask. As compared to the surgical facemask, N95 respirator does cause a higher post-wearing nasal resistance with different recovery routines. The use of $\mathrm{N} 95$ respirator by professionals for more than 4 hours resulted in tiredness and fatigue, increased $\mathrm{PaCO} 2$ and decreased $\mathrm{SpO} 2$ with resultant overall discomfort. It is mandatory in the current scenario that the people with chronic obstructive respiratory disease, cardiac ailment, or any other chronic medical conditions that make breathing difficult should check with their physician before using an N95 mask.

\section{N 95 and Surgeons}

Though not many studies are available in the journals regarding the difficulties the surgeons are facing while operating with N 95 mask along with PPE for long hours in the ongoing pandemic, the increased effort of breathing with discomfort and headache is being commonly reported. Moreover, spectacle glass misting up is also a vexing problem. The fogging effect of N95 mask is not only a tiring nuisance but even incapacitates the surgeon during surgery which can lead to a surgical error while surgery. It is recommended to wash the spectacle with soapy water before use when used with N 95 mask. Washing leaves behind a thin surfactant film that reduces the surface tension. As a result, the water molecules spread out evenly into a transparent layer, reducing the misting or fogging [6]. The surgeon must be cleanly shaven wherever the $\mathrm{N} 95$ respirator comes in contact with the face as facial hair interferes with the seal of the N 95 to the face. According to the Leo Yee Sin, Executive Director, National Centre for Infectious Diseases Singapore "If you find the N95 mask easy to breathe in and comfortable, you are wearing it wrong and it is no use... you think you are protected, but you are not." This comment holds good each time one wears N 95 mask and has been felt by all medical professionals universally in this pandemic. 


\section{Conclusion}

Masks have evolved from being just a barrier to foul smell to filters of microscopic dust and pathogens. There are different materials of mask for different settings. In the operation theatre, where procedures are high aerosol-generating, surgical masks along with N95 mask is the present recommendation. Though highly effective, the use of the $\mathrm{N} 95$ mask along with suffocating PPE, makes the surgeon's life miserable in today's scenario. Not able to breathe with rising $\mathrm{PaCo} 2$ and decreasing $\mathrm{SpO} 2$ levels, with headaches can potentially lead to many cognitive errors in surgery. Advances in mask technology that would help the surgeon breathe better and restore the joy of operating are eagerly awaited.

All authors disclose no conflict of interest. The study was conducted in accordance with the ethical standards of the relevant institutional or national ethics committee and the Helsinki Declaration of 1975, as revised in 2000 .

\section{References}

1. Christos Lynteris .Plague Masks: The Visual Emergence of AntiEpidemic Personal Protection Equipment, Medical Anthropology 2018; 37: 442-457, DOI: $10.1080 / 01459740.2017 .1423072$
2. Kam Hing Lee, Danny Tze-ken Wong, Tak Ming Ho, Ng Kwan Hoong. Dr Wu Lien-teh: modernising post-1911 China's public health service. Singapore Med J. 2014; 55: 99-102. DOI : 10.11622/smedj.2014025

3. Fischer RJ, et al. Assessment of N95 respirator decontamination and re-sue for SARS-CoV-2. medRxiv Preprint. April 15, 2020. Google Scholar DOI: https://doi.org/10.1101/2020.04.11.20062018

4. Tong PS, Kale AS, Ng K, Loke AP, Choolani MA, Lim CL, Chan YH, Chong YS, Tambyah PA, Yong E-L. "Respiratory consequences of N95-type Mask usage in pregnant healthcare workers - a controlled clinical study". Antimicrob Resist Infect Control. 2015;4:48.

DOI: 10.1186/s13756-015-0086-z. eCollection 2015.

5. Zhu JH, Lee SJ, Wang DY, et al. Effects of long-duration wearing of N95 respirator and surgical facemask: a pilot study. J Lung Pulm Respir Res. 2014;1:97-100. DOI: 10.15406/jlprr.2014.01.00021

6. Malik SS, Malik SS. A simple method to prevent spectacle lenses misting up on wearing a face mask. Ann R Coll Surg Engl. 2011;93:168. DOI: 10.1308/003588411X12851639107313b

7. Cheng VC, Yam WC, Hung IF, Woo PC, Lau SK, Tang BS, Yuen KY. Clinical evaluation of the polymerase chain reaction for the rapid diagnosis of tuberculosis. J Clin Pathol 2004;57(3):281-5. https://doi.org/10.1136/jcp.2003.012658 